\title{
Cancer Antigen 15-3 Measurement
}

National Cancer Institute

\section{Source}

National Cancer Institute. Cancer Antigen 15-3 Measurement. NCI Thesaurus. Code C103362.

The determination of the amount of the cancer antigen 15-3 in a sample. 